\title{
Telecommuting Best Practices Prior and During the COVID-19 Pandemic
}

\author{
Zlatko Bezovski ${ }^{1}$, Riste Temjanovski ${ }^{2}$, Elenica Sofijanova ${ }^{3}$ \\ UDC $\quad 331.102-027.553]: 616.98: 578.834\}-036.21(100)$ \\ ${ }^{1}$ Faculty of Economics, "Goce Delcev" University, Stip, Macedonia, \\ zlatko.bezovski@ugd.edu.mk \\ ${ }^{2}$ Faculty of Economics, "Goce Delcev" University, Stip, Macedonia, \\ riste.temjanovski@ugd.edu.mk \\ ${ }^{3}$ Faculty of Economics, "Goce Delcev" University, Stip, Macedonia, \\ elenica.sofijanova@ugd.edu.mk
}

Telecommuting, a work practice where work tasks are conducted away from a central office, was introduced in mid-1970's. While the telecommuting practices were steadily rising during the succeeding decades, they were not brought to prominence till recently. The Covid-19 pandemic and the lockdowns all around the world put many companies and employees in a position to implement work-from-home (WFH) practices, where most of the actors where not completely prepared. The experiences from these "forced" experiments range from completely positive to highly negative. Emerging studies suggest that the positive experiences motivate the companies and individuals to practice telecommuting even after the pandemic ends. In this paper we examine evidenced positive and negative aspects of telecommuting prior and during the pandemic in order to develop a list of best practices that could help companies and employees get the most out of the WFH as long as the pandemic lasts and after it ends. The areas of concern important for telecommuting we observe, include but are not limited to technology use, personal traits, working schedule, workspace, communication and management issues, work-life balance, socialization and wellbeing etc. The 7 best practices we pinpoint in our research address issues in one or more of the telecommuting areas of concern.

\section{Keywords}

Best practices, Covid-19, Telecommuting, Telework, Work from home.

\section{Introduction}

Telecommuting is a work practice where workers substitute portion of their typical work hours to work away from a central workplace [1]. Other terms used to describe such work practices, beside telecommuting, include but are not limited to remote work, work from home (WFH), freelancing, telework, virtual work, etc. Regardless that these terms may offer slightly different perspective on the same topic or different scholars may understand the term telecommuting differently, for the purpose of our work, we mainly use "telecommuting" as an umbrella term, mainly understood through the above-mentioned definition. 
The main premise of telecommuting requires working at a remote location away from a central office, typically from home, but also may include other settings like coffee shops, dispersed offices, co-workspaces, work during vacation or travel and so on. Another premise for the telecommuting practice is the use of information and telecommunication technologies (ICT) that enable communication and/or completion of work tasks. Regarding the working hours, telecommuting could range from one day away from the office per week, to full-time remote work. Workers that work full-time from home (or remotely) are known as home workers (or remote workers) and those who partially work from home are known as mixed workers.

First forms of telecommuting in the USA started to appear in the mid 70's and 80's. in ordered to address rise in oil prices, traffic congestion and air pollution [1],[2],[12], additionally, the companies realized that they could benefit if they offer more flexible work practices to their employers and started to offer work from home opportunities [1]. The development of the information and telecommunication technologies (ITC) in the following decades significantly expanded the opportunities for employees, especially information and knowledge workers, to condone work from remote locations [2].

The telecommuting practice after its introduction was rising with slow but steady pace. In the United States the proportion of employees who primarily worked from home had grown from $0.75 \%$ in 1980 to $2.4 \%$ in 2010 [3] and $4.0 \%$ in 2018. [4]. In the UK, the proportion of those working at least one day a week away from the conventional workplace grew from $13.3 \%$ in 1997 to 17.1 $\%$ in 2014 , while the proportion of those who mainly worked remotely grew from $7 \%$ in 1981 to $12.3 \%$ in 2015 [5]. Regarding the mix workers a Gallup survey suggests that in $2016,43 \%$ of the workforce in USA worked remotely at least some of the time, or 32,3\% (estimated) worked at least $20 \%$ of the time (around 1 day a week) away from the office [6]. These figures may vary from $2 \%$ to $40 \%$ in different countries where the developed countries have the lead [7].

While the telecommuting occurrence was steadily rising, the Covid-19 virus outbreak finally brought this working practice to prominence. Lockdowns and safety concerns forced many companies around the world, prepared or not, to ask their employees to work from home. A 2020 Gartner survey showed that approximately one half of the companies had more than $80 \%$ of their employees working from home during early stages of the pandemic [8]. A study from UK reported that employees who worked exclusively from home rose eight-fold from 5.7\% in January/February 2020 to 43.1\% in April 2020, and still remained high in June 2020 with 36.5\% [9]. The experiences from these enforced experiments range from highly positive to highly negative [4],[10],[11]. Nonetheless, recent studies suggest that even after the end of the pandemic, telecommuting would not return to the previous state since both, the companies and employees plan to exploit the benefits of this work practice while minimizing its negative effects.

The academic literature extensively researched telecommuting and its positive and negative aspects prior to the pandemic. Now, when the pandemic is not yet concluded, new studies emerge to address telecommuting as the "new normal" as long as the pandemic lasts, but also after it ends. In this paper we examine the best practices noted in the academic studies and throughout anecdotal evidence prior and after the covid-19 outbreak. The purpose of our work is to develop a list of the best practices that could help companies and employees get the most out of the telecommuting practices and save time experimenting by themselves.

\section{Telecommuting prior COVID-19}


It is believed that the term "telecommuting" was used for the first time in the 1970's by Jack Nilles [12], an engineer who was working remotely on NASA projects. In his book "The Telecommunications-Transportation Tradeoff', Nilles proposed telecommuting as a solution for the traffic congestion and to reduce oil consumption. Private companies such as Control Data Corporation, IBM and Ernst and Young realized that telecommuting could also be used to help address workforce issues as talent recruitment, saving on office space, addressing work-life balance of the employees etc. [1],[12].

The rise in the telecommuting practices is also attributed to the development of the information and telecommunication technologies that enabled many office workers to perform their work tasks outside the office. The internet and the personal computers were introduced in the 1980s, laptops and cell phones in the 1990s. The prices and sizes of these devices have decreased while their capacity and the internet speed and bandwidth have increased [13]. Additionally, the shift from a manufacturing towards an information economy created more jobs suitable for telecommuting.

By the end of the 1997, 10,000 federal government employees were working from home or from other remote locations [4]. In 2010, the US Government had passed the Telework Enhancement Act, that aimed to make telecommuting more effective for Federal employees. The U.S. Office of Personnel Management (OPM) in 2021 reports that that prior the pandemic there were over 500,000 federal teleworkers, what is $22 \%$ of all workers and $56 \%$ of those eligible for teleworking [15].

By the end of 2014 over 30,000 companies in the USA offered flexible job positions on the FlexJobs website among which Apple, Amazon, Dell, Xerox, Humana, Citizens Bank, Walden University and many others [16]. In 2019, 42\% of the companies in the USA offered option for part-time telecommuting to their employees [17].

While the above figures are mainly for mixed workers (part-time telecommuters), the statistics for those who mainly work remotely vary greatly from study to study mostly due to different methodology used and different understanding of the terms telecommuting, working from home or remotely working. One study [3] noted that in the United States the proportion of employees who primarily worked from home had grown from $0.75 \%$ in 1980 to $2.4 \%$ in 2010 . These figures went up to $4.0 \%$ in 2018 [4]. On the other side or the ocean, in the UK, according to Felstead and Henseke [5] the proportion of those who mainly worked remotely grew from $7 \%$ in 1981 to $12.3 \%$ in 2015 , but more recent study reported that employees who worked exclusively from home was $5.7 \%$ in February 2020 [9]. Eurofound and the ILO in 2017 report a range of $2 \%$ to $40 \%$ telecommuters, depending on country, occupation, industry, or frequency [2].

Another important trend regarding the telecommuting is the freelancing and the rise of freelancing web platforms such as Upwork, Freelancer.com, Fiverr and others. The freelancers are described as workers that are not committed to a particular employer long-term and may work full-time, parttime, on projects or on small work tasks. While freelancers are not necessarily telecommuting, they typically work from home $(86 \%)$, local coffee shop $(40 \%)$, while traveling $(25 \%)$, library or university (11\%) etc.[18]. Only $21 \%$ work at their clients' offices, $19 \%$ in co-working spaces and $15 \%$ in own offices [18] what doesn't totally exclude telecommuting as dominant behavior of the freelancers. According to a study from one of the largest freelancing platforms, Upwork, in 2019 $35 \%$ of the Americans were freelancing of which $28 \%(9,8 \%$ of the total workforce) full time, $44 \%$ part-time and $25 \%$ as an additional source of income for their regular job [19]. 
Regardless of the many noted benefits of telecommuting there are/were still negative perceptions and stigma for this working practice. For example, it is perceived that managers still value more in-office workers over those working remotely [20]. Additionally, Gajendran and Harrison note that expectations in both academic and practitioner literatures is that telecommuting has damaging effects on the quality of workplace relationships or perceived career prospects. Raffaele and Connell further note that: "There can also be the additional stigma associated with managers and co-workers viewing telecommuting as an opportunity for 'shirking ', meaning telecommuters would not be trusted to work diligently without supervision." [22]. In 2012 Yahoo's CEO Marissa Mayer announced that the company would no longer allow telecommuting to their employees [23].

All these studies and observations give mixed signals about the acceptance and prevalence of telecommuting, but it is evident that unstoppable rising trends were spotted even before the pandemic put this working practice into the public spotlight.

\section{Telecommuting during the pandemic outbreak}

The Covid-19 pandemic and the lockdowns all around the world put many companies and employees into a position to implement work-from-home (WFH) practices. Many of the actors were not completely prepared. While businesses and workers have been gradually shifting to remote work over time, the sudden outbreak of Covid-19 forced an unexpected and massive experiment for many, causing an acceleration of trends that were already underway [24]. Whereas telecommuting in the past was an option for the companies and the workforce, under the pandemic circumstances, it became imperative in order to address the concerns about the general public health.

Recent studies, in many countries across the world, discuss the effect of the Covid -19 lockdowns on telecommuting practices. In their 2020 study in the Netherlands, de Haas and colleges [25] note that in $2019,6 \%$ of respondents reported to work almost all their hours from home, while it sharply increased to $39 \%$ during the Covid outbreak. More than half (54\%) of all workers worked from home at least a part of the week. A study from UK reported that employees who worked exclusively from home rose eight-fold from 5.7\% in January/February 2020 to $43.1 \%$ in April 2020, while this proportion, fell back slightly in May 2020 to $40.8 \%$ and fell again in June 2020 to $36.5 \%$ [9].

In New Zealand $27-31 \%$ of the total workforce, between 727,000 and 777,000 people, were working full-time from home after the Covid outbreak [2]. In the US, a survey data on almost 5,000 working age adults, document that 35.2 percent of the workforce worked entirely from home in May 2020, up from 8.2 percent in February 2020 while 28.6 percent reported working from home at least once per week [26].

A 2020 Gartner survey of 229 human resources departments showed that approximately one half of the companies had more than $80 \%$ of their employees working from home during the early stages of the COVID-19 pandemic and estimated substantial long-term increases for remote work after the pandemic [27].

The shift towards telecommuting due to the pandemic is visibly represented in Table 1 where it is evident that it had significant impact on the overall working practice regardless of the previous remote working involved. 
Table 1 The rise of Remote work due Covid 19 [28]

\begin{tabular}{lcc} 
& Pre-Covid & During Covid \\
\hline Full remote teams & $2,3 \%$ & $20 \%$ \\
\hline $\begin{array}{l}\text { Mixed teams } \\
\text { (on-site and working remotely) }\end{array}$ & $13,2 \%$ & $56 \%$ to $74 \%$ \\
\hline No remote workers & $46 \%$ & $6 \%$ \\
\hline
\end{tabular}

The experiences gained from these enforced work-from-home experiments, due to the Covid-19 lockdowns, range from highly positive to highly negative [4],[10],[11]. The switch to working at home has taken its toll on the mental health of those reporting that they always or often worked at home during lockdown, but the negative effect of the change in work location subsided as workers became more accustomed to working at home [9]. The social responses captured by Dubey and Tripathi [11] through the analysis of 100,000 tweets revealed that around $73 \%$ people had a positive attitude towards teleworking while almost $27 \%$ had negative view. More than $60 \%$ tweeted with emotions of trust, anticipation and joy for remote working culture while a few reported fear, sadness, anger and disgust. "A common fear among employers is that without physical oversight employees will shirk and productivity will fall but homeworking on the whole in the lockdown did not appear to have had a significant effect on productivity levels either way" [9] where $41 \%$ of remote workers reported that they were able to get as much work done and $29 \%$ were able to do more in June 2020 than six months earlier.

According to Ozimek [28], 56\% of hiring managers feel that the shift to remote work has gone better than expected, while only one in ten feel it has gone worse than expected.

\section{Telecommuting is here to stay}

Many recent studies suggest that even after the end of the pandemic, telecommuting would not return to the previous state since both, the companies and employees plan to exploit the benefits of this work practice while minimizing the negative effects.

Firstly, as a result to the covid enforced experiment, more and more employees have higher desire to work from home. Felstead and Reuschke [9] reveal that as high as $88 \%$ of employees who worked at home during the lockdown would like to continue working at home in some capacity and $47.3 \%$ wanting to work at home often or all of the time. Another survey by Gartner in 2020 [27] suggests that $41 \%$ of employees are likely to work remotely at least some of the time post coronavirus pandemic.

On the employers' side there is also evident shift towards acceptance of more remote workers onboard. Dewi and Adiarsi [29] conducted a study with 109 executives of Indonesian Oil \& Gas companies and found that although companies were slow in adapting during the enforced WFH "experiment" in 2020, opinions shifted toward making WFH part of standard business practice. A Gartner study reveals that $74 \%$ of the companies plan to permanently shift to more remote work post covid-19, while $23 \%$ of respondent companies will move $20 \%$ or more of their employees to 
permanent remote positions post-Covid-19. Only $26 \%$ of the companies will totally abandon remote work after the pandemic ends [30].

Since the remote work experiment has gone better than expected, the perceived benefits of working remotely are triggering the companies to expand the plans for hiring remote workers in the future, which will cause an acceleration in the already upward trend of greater remote work [28].

Barrero, Bloom, and Davis [4] discuss different mechanisms that contribute towards higher prevalence of telecommuting compared to the pre-covid era. According to their study the forced experiment revealed information that speaks in favor of the telecommuting practices for both, employers and employees. In their study they capture the rise of the desire to work from home and future plans of the companies to offer more telecommuting opportunities. Additionally, the pandemic greatly diminished the stigma associated with WFH and also induced investment and innovations that enable and ease telecommuting. In the study they project that telecommuting will boost productivity by about $4.6 \%$ and that American workers will supply about 20 percent of full workdays from home in the post-pandemic economy, four times the pre-covid level [4].

Having in mind all these emerging studies it is evident that the telecommuting will keep high rates of prevalence and could become the "new normal" even after the pandemic ends. Therefore, the companies and the workers need to adopt the best practices for telecommuting as soon as possible to take most out of the remote working practices.

\section{Best practices for telecommuting}

There are many noted benefits of the telecommuting as working practice for the workers, for the companies and for the society in general. Workers who work remotely benefit from schedule flexibility, greater (perceived) autonomy, time and money saved on commuting, less work distractions, greater job satisfaction, less work-family conflict, less stress etc. [21],[28],[31]. Companies that offer telecommuting working arrangements gain by increased productivity, employee retention and commitment, new talent recruitment, office space savings [4],[12],[21],[31]. Additionally, the society also benefits from reducing air pollution and traffic congestion and also inclusion of individuals with disabilities in the labor force [2], [31].

Besides the many benefits remote working has also some negative aspects. Drawbacks of telecommuting include but are not limited to: impaired communication, damaged coworkers relations, managers' fear of control loss and shirking, employees' fear of "invisibility" and limited career advancement opportunities, overworking, social isolation, wellbeing issues (physical and mental health) etc. [2],[21],[28], [31].

Having in mind the benefits and drawbacks, it is clear that companies, employees and the society need to work (together) in order to get most of the benefits and diminish the negative aspects of telecommuting. The areas of concern we examined, in order to offer better telecommuting experiences, include but are not limited to [2],[11],[21],[24],[32]:

- Personal differences of telecommuters

- Role of technology

- Working space and working environment 
- Communication and Management issues

- Working schedule and days telecommuting

- Work-life balance, socialization, and well-being

Besides the areas of concern we observed, in order to pinpoint the best practices of telecommuting, there might be some other important issues but further, more comprehensive research is needed to include all possible aspects.

In the Table 2 we present the telecommuting areas of concern, the positive aspects, and the main challenges in each area. In the last column, based on our extensive literature review, practitioners' viewpoints, and anecdotal evidence, we suggest some best practices in order to address the main challenges. Some of these practices are explained in more details below in this paper.

Table 2: Telecommuting areas of concern and best practices

\begin{tabular}{|c|c|c|c|}
\hline Area & Positive aspects & Main challenges & $\begin{array}{c}\text { What to do? } \\
\text { (Best practices) }\end{array}$ \\
\hline $\begin{array}{l}\text { Personal } \\
\text { differences of } \\
\text { telecommuters }\end{array}$ & $\begin{array}{l}\text { - benefits for specific } \\
\text { groups } \\
\text { - telecommute better } \\
\text { suits the married, highly } \\
\text { educated, high paid } \\
\text { and knowledge } \\
\text { workers. }\end{array}$ & $\begin{array}{l}\text { - telework is not for } \\
\text { everybody } \\
\text { - appropriate treatment } \\
\text { and polices for in-office } \\
\text { and remote workers }\end{array}$ & $\begin{array}{l}\text { - option for commuting } \\
\text { - recruitment polices } \\
\text { - financial incentives } \\
\text { - flexibility } \\
\text { - support and training }\end{array}$ \\
\hline Role of technology & $\begin{array}{l}\text { - present ICT enables } \\
\text { many to work remotely } \\
\text { - already available ITC } \\
\text { (at home) } \\
\text { - enables work, } \\
\text { communication and } \\
\text { control }\end{array}$ & $\begin{array}{l}\text { - associated } \\
\text { (additional) cost for } \\
\text { companies and/or } \\
\text { employees } \\
\text { - choosing right } \\
\text { platforms } \\
\text { - learning curve for new } \\
\text { technologies }\end{array}$ & $\begin{array}{l}\text { - use free resources } \\
\text { - financial incentives } \\
\text { - invest (in updated ITC) } \\
\text { - offer training and } \\
\text { support }\end{array}$ \\
\hline $\begin{array}{l}\text { Working space and } \\
\text { working } \\
\text { environment }\end{array}$ & $\begin{array}{l}\text { - many employees } \\
\text { already have such. } \\
\text { - companies save on } \\
\text { office space }\end{array}$ & $\begin{array}{l}\text { - not all employees } \\
\text { have available, } \\
\text { destruction free space } \\
\text { at home } \\
\text { - distractions from } \\
\text { family members (and } \\
\text { pets) }\end{array}$ & $\begin{array}{l}\text { - clear (dedicated space) } \\
\text { polices } \\
\text { - flexible schedule } \\
\text { - option for commuting } \\
\text { - co-working spaces or } \\
\text { remote offices }\end{array}$ \\
\hline $\begin{array}{l}\text { Communication and } \\
\text { management issues }\end{array}$ & $\begin{array}{l}\text { - the modern } \\
\text { technology enables } \\
\text { these processes (in } \\
\text { great extent } \\
\text { - productivity could } \\
\text { increase }\end{array}$ & $\begin{array}{l}\text { - "invisible" teleworkers } \\
\text { - concern for shirking } \\
\text { - over-supervision } \\
\text { - managers' concerns }\end{array}$ & $\begin{array}{l}\text { - build trust } \\
\text { - give autonomy } \\
\text { - frequent meetings, } \\
\text { - virtual working } \\
\text { environments, } \\
\text { - goal oriented control }\end{array}$ \\
\hline $\begin{array}{l}\text { Working schedule } \\
\text { and days } \\
\text { telecommuting }\end{array}$ & $\begin{array}{l}\text { - telecommuting offers } \\
\text { great flexibility } \\
\text { - schedule could be set } \\
\text { to include personal } \\
\text { roles }\end{array}$ & $\begin{array}{l}\text { - overworking } \\
\text { - full telecommuting } \\
\text { may not be the most } \\
\text { effective } \\
\text { - manage negative } \\
\text { aspects of WFH }\end{array}$ & $\begin{array}{l}\text { - flexible hours, } \\
\text { - part-time commuting, } \\
\text { - "right to be } \\
\text { disconnected" }\end{array}$ \\
\hline Work-life balance & $\begin{array}{l}\text { - generally positive on } \\
\text { work-life balance }\end{array}$ & $\begin{array}{l}\text { - family-work conflicts } \\
\text { and destructions }\end{array}$ & $\begin{array}{l}\text { - set boundaries between } \\
\text { roles }\end{array}$ \\
\hline
\end{tabular}




\begin{tabular}{llll}
\hline & $\begin{array}{l}\text { - better cope with } \\
\text { parenting and family } \\
\text { roles }\end{array}$ & $\begin{array}{l}\text { - pressure for family } \\
\text { roles } \\
\text { - failing to separate } \\
\text { work from (family) life }\end{array}$ & $\begin{array}{l}\text { - flexible schedule } \\
\text { - dedicated space } \\
\text { - time to adapt }\end{array}$ \\
\hline $\begin{array}{lll}\text { Socialization and } \\
\text { wellbeing }\end{array}$ & $\begin{array}{l}\text { - close to family, } \\
\text { - save time on } \\
\text { commuting, }\end{array}$ & $\begin{array}{l}\text { - less socialization with } \\
\text { colleges, }\end{array}$ & $\begin{array}{l}\text { - virtual working } \\
\text { environments, }\end{array}$ \\
& - less stress. & $\begin{array}{l}\text { - distractions and family } \\
\text { conflicts } \\
\text { - physical and mental } \\
\text { health }\end{array}$ & - "socialization events, \\
& & - mixed days in-office \\
& & \\
\hline
\end{tabular}

(Source: own observations based on extensive literature review)

To address the main areas of concern and to overcome the main challenges the employers, working together with employees, need to set strategic goals and undertake certain activities in order to get most of the telecommuting practices. In many settings, practicing remote work may be a game of trial and error, but the available studies and advice from practitioners may offer practices that could serve as good starting point for the adoption process of telecommuting for many companies. These (best) practices serve to make telecommuting an overall positive experience for both the organization and the telecommuter.

The best practices derived from our research, that addresses some or more of the main areas of concern and challenges, include:

- Companies and managers need to nurture telecommuting culture

- Telecommuting should be offered as an option

- Offer flexible schedule and greater autonomy

- Offer/require mixed days (part-time) telecommuting

- Use of updated technology and provision of support and training

- Require (and incentivize) dedicated working space and work-life boundaries

- Staying connected through different communication and collaboration channels

Besides the above-mentioned, there are more potentially beneficial practices that we intentionally neglected or omitted in our research due to time constrains. Further, more detailed, research may try to identify and examine additional areas of concern or to address more specific issues. Since the "forced" telecommuting experiment due Covid-19 is still in practice, additional concerns may appear or become more prominent.

Below, we examine and explain the noted best practices in more details.

\subsection{Nurture telecommuting culture}

It seems that the stigma for telecommuters and working from home arrangements has been greatly overcome due to the Covid-19 enforced experiments [4] but it is still stays that companies need to manage the trust issues and to nurture positive climate toward telecommuting. For organizations that do offer telecommuting, as with any organizational practice, support from the organization is needed for it to be effective [1]. A supportive telecommuting/work environment 
ensures a 'normative' experience of telecommuting and builds confidence in the telecommuter, social engagement of teleworkers outside work hours can improve perceptions of 'visibility' [11].

In a case study of a US-based company in 2016, it was found that the company had taken "a number of steps to create a successful flexibility program and to promote a supportive culture that is beneficial for managers", primarily because of the possibility that engagement between the telecommuting employee and the manager may decrease over a long period as trust and confidence in goal attainment are assured. [11]

WFH as an alternative working arrangement can be viewed as an organizational and human resource innovation which introduction involves adjustment of the organization in terms of its governance structure, coordination and control mechanisms, relationships and reward systems [2]. Telecommuting programs need to be crafted, written and agreed to, not assumed. WFH arrangements need to be formalized, respected and adhered to [11]. Guidelines for telecommuting must be set up and adhered to by both the telecommuter and the organization. Managers must respect their telecommuters and ensure their inclusion in the structure of the organization. Effective communication between telecommuters and managers/supervisors, with the use of proper ICT platforms amongst other means, can ensure optimal work performance and build trust, while mutually agreed boundary settings and WFH arrangements are key to effective and productive telecommuting. [11] The evidence and theory suggest that the downside of higher intensity telecommuting, that harms the coworker relationships, can be managed effectively through informed human resources policies. [21]

Setting a corporate culture favorable for telecommuting would lead the organization and all of its employees, including the managers, to more effective teleworking practices. The corporate culture should reflect into the written polices regarding telecommuting in order to get most out of these remote working agreements.

\subsection{Telecommuting should be an option}

There are differences among workers for preference of telecommuting depending on personality type. It is noted that employees who are more introverted and open to the idea of telecommuting tend to have a more positive experience, while individuals who are extroverted and desire to have a strong boundary between work and home tend to find telecommuting a more negative experience [33]. Besides the personal traits and preference for telecommuting the educational background, experience, job position, the industry, age, gender and family status may play important role for positive outcomes of the telecommuting practice [2],[4],[9],[11],[21], [26]. It is suggested that the benefits of telecommuting will flow mainly to older, women, those with children, longer commuters, highly educated, experienced and the well-paid workers. Additionally, telework is more suitable for specific industries, professions or job positions.

In their study, Masuda and colleges [34], found that employees given the opportunity to telecommute were more likely to perceive higher support in attaining work goals, and consequently showed higher goal achievement [11]. On the other hand, if telecommuting is not on voluntary bases is not well received and could bring tension and conflicts among employee and the organization [35].

Having in mind the personal traits, preferences, and different backgrounds, telecommuting and working from home should be a matter of choice for the employees since not everyone wants or 
could effectively work remotely. When employees have choice to work ether in office or from home, studies suggest, will have greater job satisfaction, and would perform better.

\subsection{Flexible schedule and greater autonomy}

One of the greatest benefits of telecommuting is the ability to have flexible working hours in order to achieve a better work-life balance and to use the time more effectively according to the personal preferences of the workers.

The academic studies offer significant evidence that allowing control over working schedules makes job offers more attractive to potential workers [36]. In contrary, the study by Kaduk and colleges in 2019 found that involuntary or enforced flexibility arrangements requiring different work schedules are not well received [35].

Regarding the autonomy, a research from 2007 suggests that perceived autonomy is pivotal for maximizing telecommuting beneficial outcomes [21]. Additionally, Gajendran et al. in 2015 [37] found that when the employee is allowed a certain degree of autonomy, relying strongly on the supervisor's trust of the employee to achieve work goals, improved performance at any intensity of telecommuting. On the other hand, lack of trust might lead to excessive surveillance and monitoring efforts where such pressures lead to teleworkers working extensive hours to 'overcompensate' as fears of 'not doing enough [38]. Extreme telecommuting supervision leads to increasing fears of losing a job, stress, and adverse mental health outcomes. [11] and other possible negative consequences for organizations [21].

Undoubtedly, the studies suggest that besides offering flexible scheduling arrangements for their remote workers, the employers need to set goal focused outcomes. Such can benefit both telecommuters and supervisors especially when a degree of autonomy and control is afforded to the telecommuter [11]. In order to achieve that, a priori, more trust-based strategy could be to create written telecommuting agreements that clearly lay out managerial expectations about work outcomes without neutralizing the autonomy of the telecommuter so he or she can choose how and when performance goals will be achieved [21].

\subsection{Mixed days in-office and telecommuting}

The two extremes regarding telecommuting are full time arrangement (no office time) or no (or occasional) working hours at remote locations. Studies suggest that the sweet spot for best outcomes of telecommuting lie somewhere in between these poles. Gajendran and Harrison [21] found that home-centered or high-intensity telecommuting accentuated its beneficial effects on work-family conflict but at the same time it led to deterioration of coworker relationships. "Evenlysplit part-time telework arrangements are optimal for telecommuter satisfaction, allowing regular interactions with work colleagues while permitting flexible schedules" [11]. WFH did not significantly harm collegial relationships, especially if telecommuting was not exceeding 2.5 days per week [21]. More than two or three days per week, is associated with negative impacts on work and family relationships blurring of the lines between the two [2].

Basile and Beauregard in 2016 [39] found that for full-time telecommuters isolation was negatively associated with performance, while part-time telecommuters had a negligible perceived impact of isolation on performance. Regarding the salary levels, the mixed workers had higher averages compared to fulltime telecommuters and full time in-office workers [9]. 
Bloom, based on his past studies, suggests Tuesday and Thursday as telecommuting days since office days are needed for face-to-face meetings, motivation, creativity and developing new ideas [40].

If we take in consideration all these studies and suggestions, it seems that the ideal work week would be comprised of three days in the office and two days telecommuting. Anyway, many organizations would decide to offer exclusive work from home arrangements (many already do) but they must be aware of the possible negative effects of full-time telecommuting and must find appropriate measures to address such issues.

\subsection{Use updated technology and provide support and training}

Important premise for telecommuting is the use of information and communication technologies (ICT) that enable performance of work tasks, supervision and effective communication with managers, colleges, business partners and clients. Despite technological advances, the provision of sufficient technology that is compatible and underpinned by ICT policies continues to be a challenge for telecommuting [2].

The sudden shift to WFH in reaction to Covid-19 spurred workers and firms to additionally invest in physical, human, and organizational capital that, in turn, improves WFH capabilities [4]. The technologies that enable and enhance telework include high-speed internet, management software, messenger communication systems, computing hardware, smartphones [11], teleconferencing software, remote collaboration tools, etc. [4]. Besides the hardware and software components of the telecommuting technology the broad-band internet is also very important. In countries where high-quality internet penetrance is prevalent, the prevalence of telecommuting is on the rise, while in countries where such technology is not highly present, telecommuting can be hindered to a significant degree [11].

Technology plays a vital role in alleviating the potential disadvantages of telecommuting, namely social isolation and difficulties with communication and collaboration [2]. Since working from home can lead to social and professional isolation that hampers knowledge sharing and job prospects the adoption of suitable platforms that facilitate cooperation and knowledge sharing may help optimize the performance of teams [11]. Developing telepresence systems provide an immersive experience that more closely mimics that of colocation and research shows that higher social richness and higher telepresence result in greater telecommuter motivation and greater sustained use of the system [1]. As technological advancements continue, it becomes easier for individuals to work remotely further limiting the disadvantages associated with telecommuting.

Support and training for workers using technology while WFH is also important for enabling workers to maintain their performance at work [2]. Also, there is a learning curve associated with adjusting to telecommuting. As employees spend greater time working under this arrangement and as they spend a greater proportion of their work remotely, they learn to structure tasks and routines to minimize conflicts between work and family demands and to mitigate the stresses of juggling multiple roles [21]. Organization administrators need to be trained in the implementation of telecommuting programs, especially regarding expectations, monitoring, supervising, measuring, and evaluating performance [11]. 
Use of up to-date technology and providing support and training for the employees is very important aspect to ensure better outcomes of the telecommuting working practices. Besides enabling company's telecommuting tools and resources (on-premise or in could), the company needs to make sure the employees meet specific technology standards in order to have undisrupted telecommuting experience. If employees don't possess the needed equipment the company may offer some incentives and/or may set clear teleworking standards and polices regarding the needed ICT.

\subsection{Dedicated workspace and work-life boundaries}

Anyone who had a chance to work remotely could notice that having dedicated space to perform working tasks would be the best environment for telecommuting free from distractions. Having own room was one of the factors for preference of telecommuting over in-office arrangements [4]. Remote workers who have strategies to segment work and family, as dedicated workspace, have been reported to have the lowest work-family conflict [41].

Successful tips for working from home referred by Hope include creating a space dedicated to work, maintain a work schedule, separate work from housework and setting boundaries with other household members [42]. Telecommuters can use physical, temporal, behavioral and communicative strategies to create boundaries similar to that of the office environment [43].

Managers should be able to "suggest and possibly have influence on the setup of telecommuting at home, along with provisions of equipment and suggestions on boundaries and space where ideally, a home-based office space should be pleasant and ergonomic, ensuring a healthy work environment" [11].

Regarding the work-life balance it is noted that telecommuting can urge remote workers to overwork as work is always 'right there', and this can create work-family conflict negatively impacting on wellbeing and mental health [2]. Therefore, setting boundaries remains an integral part of telecommuting arrangements, and positive outcomes can only be ensured with the establishment of clear polices that limit negative consequences of spillover of work into hometime and minimize work-family conflicts [11]. In addition to worker behavior, organizations need to create a culture, along with policies, that enable workers to disconnect from work termed as 'the right to be disconnected' [7].

Alternative form for establishing separate workspace and maintaining work life balance is to use remote offices or co-working spaces. Working in coffee shops, libraries or while traveling may not offer the needed destruction free and formal environment for performing job tasks. Co-working spaces may be also favorable for addressing the social isolation issue [11].

Since having dedicated space for remote working and maintaining work-life balance is very important for positive outcomes of the telecommuting arrangement, companies need to treat this issue with caution. Dedicated workspace could be requested through clear telework arrangement and recruitment policies for new employees, or the company could offer schedule and/or location flexibility for current employees if they do not possess such working spaces at home. Financial and other incentive could also be offered for the employees in order to obtain or set appropriate working space. 


\subsection{Stay connected}

Some of the analyzed areas of concern regarding the telecommuting (Table 2) are becoming hurdle for effective work mainly due to lack of face-to-face interaction among team members including the interactions with peers, with managers, and with subordinates. The lack of direct, face-to-face interaction mostly brings up communication and management issues but also socialization and wellbeing concerns for the telecommuters. One way to address these issues and diminish the negative effects is by offering mixed in-office and telecommuting days, while the other is through effective means of communication and collaboration enabled by the modern and up-to-date information and telecommunication technologies.

Effective communication and collaboration is needed to address specific issues in order to:

- manage the damaged coworker relationships [21],

- ensure inclusion and visibility of telecommuters in the mixed teams [11],

- address the managers' concerns for shirking [2],

- build relationship and sense of togetherness among workers [1],[2],[11],

- improve information flow, coordination, decision making, productivity [4], [11] etc.

Communication and collaboration can be limited by WFH and is an often-cited reason for organizations not to adopt telecommuting, while, on the other hand, technological tools such as online collaboration tools, web-based presentation rooms, workflow management tools and desktop video conferencing can be used to enhance collaboration [2]. Effective management is also important in WFH environments requiring "relationship-orientated behaviors" with a focus on clear and frequent communication [44]. Communication in a telecommuting context should be more explicit than it might be in a comparable in-person interaction [45]. Clear work objectives with realistic goals need to be communicated through multiple channels, determined by the preferences of workers [2]. Guidelines are required and discussion discipline needs to be maintained, especially during remote meetings, ensuring smooth communication and effective time management [11]. Managers also need to ensure effective communication between telecommuters and non-telecommuters in order to include telecommutes in the ongoings of the organization [46].

Telecommuting can result in social and professional isolation that can hinder job performance and negatively affect the telecommuter's wellbeing [2],[11]. Organizational social support and use of rich communication technologies such as videoconferencing [2] and Google Hangouts [1] could address this issue. Managers could help telecommuters build relationships with peers by planning social events and providing means of informal communication, learning, and mentoring [45].

So, in order to address challenges as communication, coordination, supervision, trust, visibility and socialization with coworkers, teams with remote members need to stay connected through different channels and probably more often than in regular, office settings. This could be achieved buy use of appropriate technology (teleconferencing, chat, collaboration platforms, file sharing systems, virtual offices etc) and arranging regular online and in-office meetings in accordance with the needs. Special socialization events (online or offline) could be also organized to address the issue of impaired socialization due to telecommuting. Co-working spaces and/or remote offices may also cope with socialization issues concerning teleworkers. 


\section{Conclusion}

Telecommuting as a work practice, otherwise known as remote-work or work-from-home, was steadily rising in the past decades but without significant public prominence. The Covid-19 pandemic enforced many companies to send their employees to work from home, what finally brought this promising working practice to the public spotlight.

There were many noted benefits of the telecommuting for the workers, for the companies and for the society even before the pandemic. Employees who work remotely benefit from schedule flexibility, greater (perceived) autonomy, time and money savings, less work distractions, greater job satisfaction, less work-family conflict, less stress etc. Employers of remote workers gain by increased productivity, higher employee retention, more talent recruitment options, office space savings and so on. The society benefits from less air pollution, lower traffic congestion and inclusion of individuals with disabilities in the labor force.

Since emerging studies suggest that prevalence of remote working practices will stay high even after the pandemic ends, it is clear that employers and employees need to adopt proven practices for telecommuting in order to get the most out of this working practice in a shorter period of time. The best practices that address the main concerns and challenges for telecommuting, pinpointed in our research include:

1. The companies and managers need to nurture telecommuting culture

2. Telecommuting should be offered as an option

3. Flexible schedule and greater autonomy

4. Mixed days (part-time) telecommuting

5. Use of updated technology and provision of support and training

6. Dedicated working space and work-life boundaries

7. Staying connected through different communication and collaboration channels

Sine the companies are all different, operate in different industries, have different mixes of onsite, administrative or knowledge workers, have different levels of previous experience in teleworking and so on, introduction and rise of lasting telecommuting practices may become a game of error and trial in the years that come. Anyway, the best practices we offer could serve as a solid starting point for adoption of remote working practices, based on scientific research and noted practitioners' experiences. These (best) practices derived from our study may help telework become an overall positive experience for both, the organization and the telecommuter. After the initial introduction of the remote working practices, the companies and workers may need to adjust or change their methods in order to better address their particular characteristics.

\section{References}

1 Allen TD, Golden TD, Shockley KM. How effective is telecommuting? Assessing the status of our scientific findings. Psychological Science in the Public Interest. 2015 Oct;16(2):40-68.

2 Green N, Tappin D, Bentley T. Working from home before, during and after the Covid-19 pandemic: implications for workers and organisations. New Zealand Journal of Employment Relations. 2020 Jan;45(2):5-16.

3 Mateyka PJ, Rapino M, Landivar LC. Home-based workers in the United States: 2010.

4 Barrero JM, Bloom N, Davis SJ. Why working from home will stick. 2021 
5 Felstead A, Henseke G. Assessing the growth of remote working and its consequences for effort, wellbeing and work-life balance. New Technology, Work and Employment. 2017 Nov;32(3):195-212.

6 Gallup I. State of the American workplace. Retrieved from Gallup. com website: https://www. gallup. com/workplace/238085/state-american-workplace-report-2017. aspx. 2017

7 Eurofound IL. Working anytime, anywhere: The effects on the world of work. Luxembourg, Geneva. 2017.

8 Kniffin KM, Narayanan J, Anseel F, Antonakis J, Ashford SP, Bakker AB, Bamberger P, Bapuji H, Bhave DP, Choi VK, Creary SJ. COVID-19 and the workplace: Implications, issues, and insights for future research and action. American Psychologist. 2021 Jan;76(1):63.

9 Felstead A, Reuschke D. Homeworking in the UK: before and during the 2020 lockdown. 2020

10 Dubey AD, Tripathi S. Analysing the sentiments towards work-from-home experience during covid-19 pandemic. Journal of Innovation Management. 2020 Apr 28;8(1):13-9.

11 Karanikas N, Cauchi J. Literature review on parameters related to Work-From-Home (WFH) arrangements. 2020

12 Narayanan L, Menon S, Plaisent M, Bernard P. Telecommuting: The work anywhere, anyplace, anytime organization in the 21st century. Journal of Marketing \& Management. 2017 Nov 1;8(2):47-54.

$13 \mathrm{Kizza}$, J. M. (2013). Ethical and social issues in the information age. London, England: Springer-Verlag - as cited in Allen, T. D., Golden, T. D., \& Shockley, K. M. (2015). How effective is telecommuting? Assessing the status of our scientific findings. Psychological Science in the Public Interest, 16(2), 4068.

14 Avery C, Zabel D. The flexible workplace: A sourcebook of information and research. 2001

15 U.S. Office of Personnel Management (OPM), Status of Telework in the Federal Government - Report to Congress - Fiscal Year 2019, March 2021

16 Reynolds, B.W. 100 Top Companies with Remote Jobs in 2015. FlexJobs Job Search Tips and Blog. FlexJobs.com, January 20, 2015. https://www.flexjobs.com/blog/post/100-top-companies-with-remotejobs-in-2015

17 Society for Human Resource Management (SHRM). Leave and flexible working - 2019 Employee Benefits Survey https://www.shrm.org/hr-today/trends-and-forecasting/research-andsurveys/pages/benefits19.aspx

18 The Slash Workers. And.co. 2016 [2021 Jun 18]. Available from: https://www.and.co/slash-workers.html

19 Ozmek Adam, Report: Freelancing and the Economy in 2019 | Upwork," Upwork.com, https://www.upwork.com/press/releases/freelancing-and-the-economy-in-2019 . 2019

20 Carpenter, Julia. The downside of working from home CNN, January 24, 2019. Available from: https://edition.cnn.com/2019/01/24/success/remote-worker-bias/index.html.

21 Gajendran RS, Harrison DA. The good, the bad, and the unknown about telecommuting: meta-analysis of psychological mediators and individual consequences. Journal of applied psychology. 2007 Nov;92(6):1524.

22 Raffaele C, Connell J. Telecommuting and co-working communities: what are the implications for individual and organizational flexibility?. Flexible work organizations. 2016:21-35.

23 Tkaczyk C. Marissa Mayer breaks her silence on Yahoo's telecommuting policy [Internet]. Fortune. Fortune; 2013 [cited 2021 Jun 18]. Available from: https://fortune.com/2013/04/19/marissa-mayerbreaks-her-silence-on-yahoos-telecommuting-policy/

24 Kniffin KM, Narayanan J, Anseel F, Antonakis J, Ashford SP, Bakker AB, Bamberger P, Bapuji H, Bhave DP, Choi VK, Creary SJ. COVID-19 and the workplace: Implications, issues, and insights for future research and action. American Psychologist. 2021 Jan;76(1):63.

25 de Haas M, Faber R, Hamersma M. How COVID-19 and the Dutch 'intelligent lockdown'change activities, work and travel behaviour: Evidence from longitudinal data in the Netherlands. Transportation Research Interdisciplinary Perspectives. 2020 Jul 1;6:100150.

26 Bick A, Blandin A, Mertens K. Work from home after the COVID-19 Outbreak.2020

27 Gartner. Gartner HR survey reveals $41 \%$ of employees likely to work remotely at least some of the time post coronavirus pandemic. Newsroom. Retrieved from https://www.gartner.com/en/newsroom/pressreleases/2020-04-14-gartner-hr-survey-reveals-41--of-employees-likely-to- . 2020

28 Ozimek A. The future of remote work. Available at https://papers.ssrn.com/sol3/papers.cfm?abstract_id=3638597. 2020 May 27.

29 Dewi I, Adiarsi GR. Leveraging the COVID-19 crisis in making work-from-home a mainstream practice in the oil and gas industry. International Journal of Multicultural and Multireligious Understanding. 2020 Jul 10;7(6):305-16. 
30 Lavelle J. Gartner CFO survey reveals $74 \%$ intend to shift some employees to remote work permanently. [cited 2021 Jun 18]. Available from: https://www.gartner.com/en/newsroom/press-releases/2020-04-03gartner-cfo-surey-reveals-74-percent-of-organizations-to-shift-some-employees-to-remote-workpermanently2

31 Green CR. Examining the effects of negative work outcomes on telecommuting (Doctoral dissertation, Middle Tennessee State University) 2019

32 Varty CT, O'Neill TA, Hambley LA. Leading anywhere workers: A scientific and practical framework. In Anywhere working and the new era of telecommuting 2017 (pp. 47-88). IGI Global.

33 Anderson AJ, Kaplan SA, Vega RP. The impact of telework on emotional experience: When, and for whom, does telework improve daily affective well-being?. European Journal of Work and Organizational Psychology. 2015 Nov 2;24(6):882-97

34 Masuda AD, Holtschlag C, Nicklin JM. Why the availability of telecommuting matters: The effects of telecommuting on engagement via goal pursuit. Career Development International. 2017 May 8.

35 Kaduk A, Genadek K, Kelly EL, Moen P. Involuntary vs. voluntary flexible work: insights for scholars and stakeholders. Community, Work \& Family. 2019 Aug 8;22(4):412-42.

36 di Domenico M, Daniel E, Nunan D. 'Mental mobility'in the digital age: entrepreneurs and the online home-based business. New Technology, Work and Employment. 2014 Nov;29(3):266-81.

37 Gajendran RS, Harrison DA, Delaney-Klinger K. Are telecommuters remotely good citizens? Unpacking telecommuting's effects on performance via i-deals and job resources. Personnel Psychology. 2015 Jun;68(2):353-93.

38 Wheatley D. Employee satisfaction and use of flexible working arrangements. Work, employment and society. 2017 Aug;31(4):567-85.

39 Basile KA, Beauregard TA. Strategies for successful telework: How effective employees manage work/home boundaries. Strategic HR review. 2016 Jun 13.

40 Bloom N. The bright future of working from home | SIEPR [Internet]. Stanford.edu. 2020 [cited 2021 Jun 23]. Available from: https://siepr.stanford.edu/research/publications/bright-future-working-home

41 Eddleston KA, Mulki J. Toward understanding remote workers' management of work-family boundaries: The complexity of workplace embeddedness. Group \& Organization Management. 2017 Jun;42(3):34687

42 Hope J. Working from home? Follow these tips for successful remote work. The Successful Registrar. 2020 May;20(3) https://doi.org/10.1002/emt.30655

43 Boccabella D, Bain K. The age of the home worker-part 1: Deductibility of home occupancy expenses. Austl. Tax F.. 2018;33:827.

44 Dahlstrom TR. Telecommuting and leadership style. Public Personnel Management. 2013 Sep;42(3):438-51.

45 Makarius EE, Larson BZ. Changing the perspective of virtual work: Building virtual intelligence at the individual level. Academy of Management Perspectives. 2017 May;31(2):159-78.

46 Piszczek MM. Boundary control and controlled boundaries: Organizational expectations for technology use at the work-family interface. Journal of Organizational Behavior. 2017 May;38(4):592-611. 